\title{
Energy simulation and feasibility of a Ground-Source Heat Pump coupled with a Phase Change Material energy storage system for heat supply.
}

\author{
J. M. García-Alonso ${ }^{1}$, F. Aguilar ${ }^{1}$ and E. Montero ${ }^{1}$ \\ ${ }^{1}$ Department of Electromechanical Engineering \\ Escuela Politécnica Superior, University of Burgos \\ Avenida Cantabria s/n, 09006 Burgos (Spain) \\ Phone number: +0034947 258 916, e-mail: jmgalonso@ubu.es, faguilar@ubu.es, emontero@ubu.es
}

\begin{abstract}
.
The Zero Energy Building concept is conceived as a solution for the mitigation of $\mathrm{CO}_{2}$ emissions and the reduction of energy use in the building sector. Heat pumps are considered as highefficiency alternative systems to contribute to reduce energy consumption in buildings, particularly when they are based entirely or partially on energy from renewable sources, such as ground energy. Combined use of Ground-Source Heat Pumps (GSHP) with Phase Change Materials (PCM) energy storage systems could improve even more the energy efficiency, and reinforce the approach to Zero Energy Building. Moreover, the PCM energy storage allows the owner to use low-cost electricity periods (night, weekend) to operate the GSHP, thanks to the delay between the energy charging period and the user needs. This work deals with the simulation and feasibility of a GSHP+PCM facility, designed to meet the domestic hot water (DHW) and heating energy needs of a standard single family house placed in a European continental climate.
\end{abstract}

\section{Key words}

Ground-source heat pumps, phase change materials, energy storage, long term economy.

\section{Introduction}

The Zero Energy Building (ZEB) concept is no longer perceived as a concept of a remote future, but as a realistic solution for the mitigation of $\mathrm{CO}_{2}$ emissions and the reduction of energy use in the building sector. The increasing number of ZEB demonstration projects and research interest in the field internationally highlights the growing attention given to ZEBs. The recast of the Directive on Energy Performance of Buildings (EPBD) [1] adopted in May 2010 establishes the 'nearly zero energy building' as the building target from 2018 for all public owned or occupied by public authorities buildings and from 2020 for all new buildings. The EPBD also promotes the technical, environmental and economic feasibility of high-efficiency alternative systems such as decentralised energy supply systems, cogeneration, district heating or cooling and heat pumps. These systems are more interesting particularly when they are based entirely or partially on energy from renewable sources.

Ground-Source Heat Pumps systems (GSHP) are one of the fastest growing applications of renewable energy in the world. Since a GSHP system does not directly create any combustion products and because it draws additional free energy from the ground, it can actually produce more energy than it uses. GSHP systems are more efficient than air-source heat pumps, which exchange heat with the outside air, due to the stable, moderate temperature of the ground. They are also more efficient than conventional heating and air-conditioning technologies. For the above reasons, significant energy savings can be achieved through the use of GSHPs in place of conventional air-conditioning systems and airsource heat pumps.

Combined use of GSHP with Phase Change Materials (PCM) energy storage systems could improve even more the energy efficiency, and reinforce the approach to ZEB. The PCM provides a very stable temperature system that, combined with the stable temperature of the ground, will lead to high seasonal coefficients of performance of the GSHP [2-5]. Moreover, the PCM energy storage allows the owner to use low-cost electricity periods (night, weekend) to operate the GSHP, thanks to the delay between the energy charging period and the user needs. This work deals with the simulation and feasibility of a GSHP+PCM facility, designed to meet the domestic hot water (DHW) and heating energy needs of a standard single family house placed in a European continental climate.

\section{Objectives}

The interest of the general study is to couple the PCM modules with a GSHP open loop system, in order to reach the following advantages: 


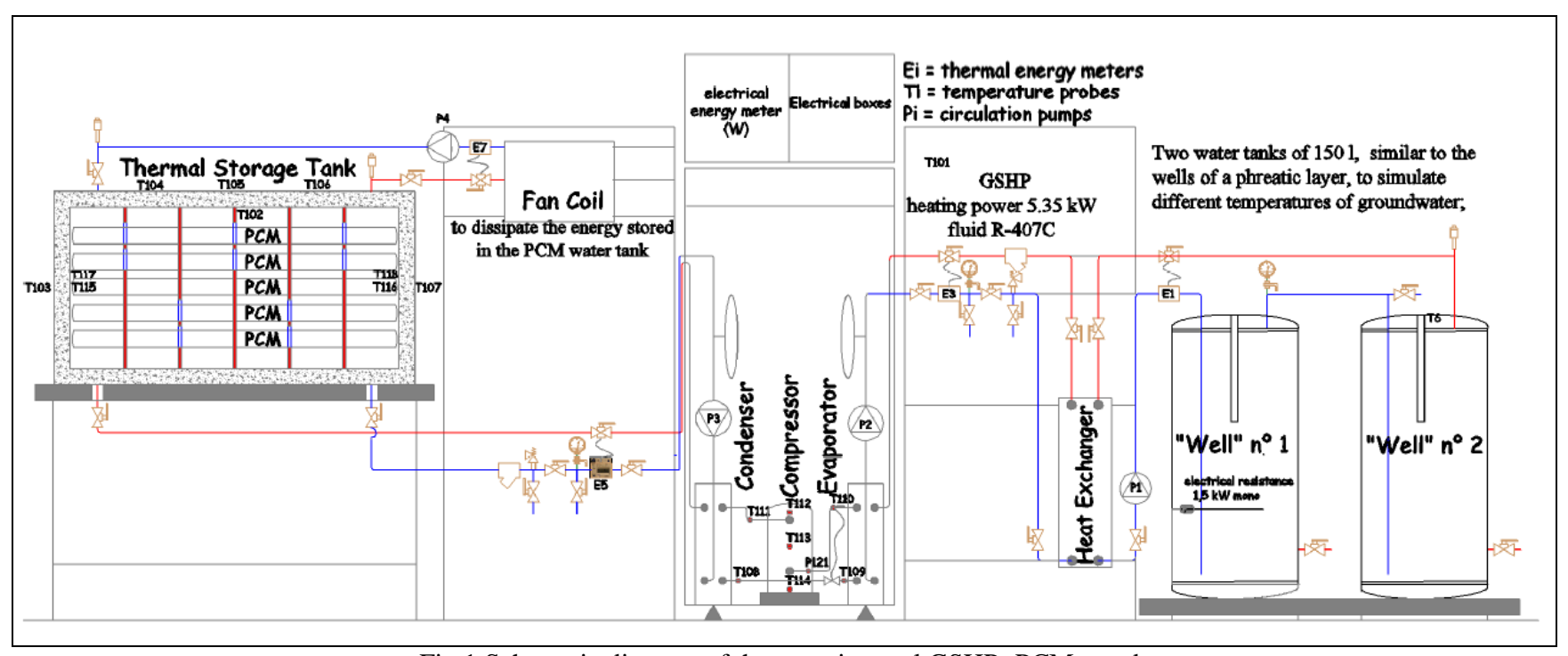

Fig.1 Schematic diagram of the experimental GSHP+PCM stand.

1) Energy: To reduce total energy consumption.

2) Space: To reduce the volume of the energy storage

3) Low cost: To use low electricity costs (night tariff), charging the PCMs during the night and discharging them during the day.

4) Long term economy: To improve the return on investment compared to conventional facilities.

5) Environment: To reduce de $\mathrm{CO}_{2}$ emissions compared to conventional facilities.

This paper deals only with the energy consumption of the system.

To test the energy efficiency and technical feasibility of the coupled system GSHP+PCM, an experimental stand has been constructed at the University, as shown in Fig. 1. It consists of (A) two water tanks of 1501 , similar to the wells of a phreatic layer, to simulate different temperatures of groundwater; (B) one GSHP (heating power $5.35 \mathrm{~kW}$, fluid R-407C); (C) one storage tank of 2001 , filled with the PCM modules (phase change temperature $48^{\circ} \mathrm{C}$ ); (D) One fan-coil, to dissipate the energy stored in the PCM water tank, simulating its use in a single family house of about $150 \mathrm{~m}^{2}$. For energy calculation purposes, the experimental stand was equipped with four thermal energy meters $(E)$ and one electrical energy meter (W).

A comprehensive computer program, using Engineering Equation Solver EES software (CF-Chart Software, LLC), has been developed to simulate the coupled GSHP+PCM system, which accounts for the effectiveness of the GSHP in relation to the energy balance of our installation. The aim is to compute the energy efficiency of the installation during the loading, storage and downloading energy processes and therefore to allow us to perform simulations of real scenarios to verify the feasibility of this technology. Transient cases are of utmost interest for the user.

The program is flexible enough to consider several options: houses with different surface and shape, floor heating, radiators, fan-coils, etc., and, even, located in different climatic zones, providing for both energy and economic operation.

The developed program also allows to assess energy efficiency on the refrigeration cycle and components of the GSHP.

\section{Case Study.}

The case study presented in this paper consists of the simulation of a single family house in the following conditions:

1) Climatic zone: continental climate

2) Energy emitter: radiant floor heating

3) Daily energy demand: $96 \mathrm{kWh}$

4) Heating energy generator: GSHP.

5) Thermal Energy Storage (TES): water tank or PCM

Some assumptions and operating restrictions have been considered:

1) The uniform distribution of heat energy demanded by the house

2) The period of operation of the GSHP is only 14 hours a day

3) The minimum water temperature in the Thermal Energy Storage (TES) is $30^{\circ} \mathrm{C}$

The parameters simulated and evaluated are (i) the evolution of the temperature of the storage tank, and (ii) the availability of stored energy for the user. Also the energy and exergy analysis of the system have been performed.

A comparative study between two possible facilities has been done, in order to analyze what is more effective:

1) Case 1: GSHP + sensible TES: Thermal energy is produced by the GSHP for 14 hours a day and stored in the water tank as sensible heat to meet 
daily energy demand. This situation requires large volumes of water at high temperature.

2) Case 2: GSHP + latent TES: In this case the energy is stored as sensible heat + latent heat (PCM), that thereby reduces the volume of water needed and the storage temperature.

For the two cases considered, energy and exergy balances and efficiencies are provided for the overall process. Three steps are involved during the process of thermal energy storage:

\section{Charging period:}

Energy input - Energy loss $=$ Energy accumulation

II. Storing period:

- Energy loss = Energy accumulation

III. Discharging period:

$-($ Energy recovered + Energy loss $)=$ Energy accumulation

where:

Energy input: energy given by the GSHP to the TES

Energy loss: energy transfer from the TES to its surroundings (convection, radiation, etc.)

Energy recovered: energy exit from the TES to the dissipation system (fan-coil, radiant heating floor, etc.)

Energy accumulation: energy stored in the TES

The overall Energy Balance for the storage process can be written as:

$$
\begin{gathered}
\text { Energy input }-\left(\begin{array}{c}
\text { Energy recovered }+ \text { Energy loss }) \\
\text { Accumulation. }
\end{array}\right. \\
\text { Energy }
\end{gathered}
$$

and the overall Exergy Balance can be written as:

$$
\begin{gathered}
\text { Exergy input }-(\text { Exergy recovered }+ \text { Exergy loss })-\text { Exergy } \\
\text { consumption }=\text { Exergy accumulation }
\end{gathered}
$$

being the Exergy consumption the exergy due to thermodynamic irreversibilities.

Some physical assumptions are involved in the energy calculations: (i) all the thermo-physical properties (density, latent heat, melting temperature, specific heat capacity and thermal conductivity) of PCM are constant, both at solid and liquid phase; (ii) nucleation and supercooling are assumed not to be present in PCMs; (iii) influence of the thermal conductivity of the encapsulating material is negligible; (iv) the two-phase Stefan model of melting [2] is assumed.

Evaluation criteria followed for the validation of the simulation program has been based on comparing trends between preliminary experimental data [6] and those obtained by the simulation program. Deviation between experimental a simulated data have been estimated to be less than $1 \%$ in the temperature of the storage tank. Fig. 2 shows the graphical comparison between measured and simulated data.

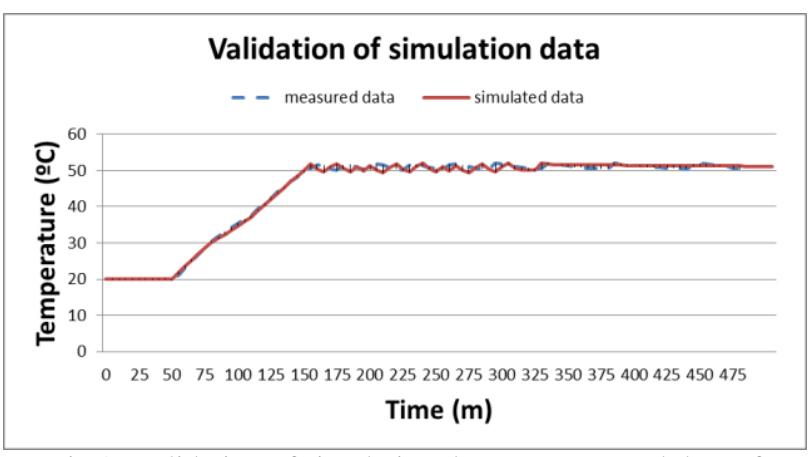

Fig.2. Validation of simulation data vs. measured data of GSHP+TES system.

\section{Results and discussion.}

To meet the daily thermal energy demand of $96 \mathrm{kWh}$ of the house, the simulated size of the respective equipment is

1) Case 1:
a. GSHP: $14 \mathrm{~kW}$ heating power
b. Sensible TES (water): 1000 litres
c. Storage temperature set point: $65^{\circ} \mathrm{C}$

1) Case 2:
a. GSHP: $10 \mathrm{~kW}$ heating power
b. Latent TES (PCM): 400 litres
c. Storage temperature set point: $40^{\circ} \mathrm{C}$

Detailed results of case simulations are presented below in terms of the evaluated parameters.

i. Evolution of the temperature of the TES

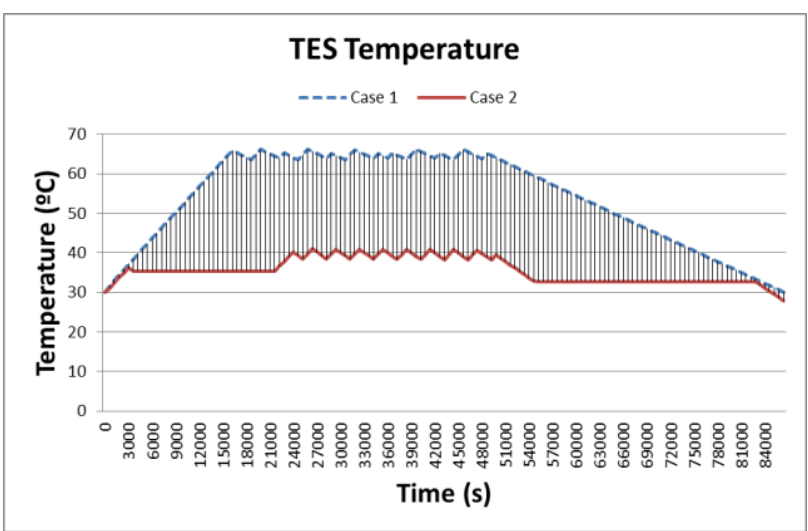

Fig. 3 TES temperature $\left({ }^{\circ} \mathrm{C}\right)$

Figure 3 shows the evolution of temperature over time. It can be appreciated that the temperature is lower and more stable in the case of latent TES (PCM). It means that energy losses will be lower in Case 2 than in Case 1, due to lower temperature differences between the storage tank and the ambient temperature. 


\section{ii. Availability of the stored energy for the user}

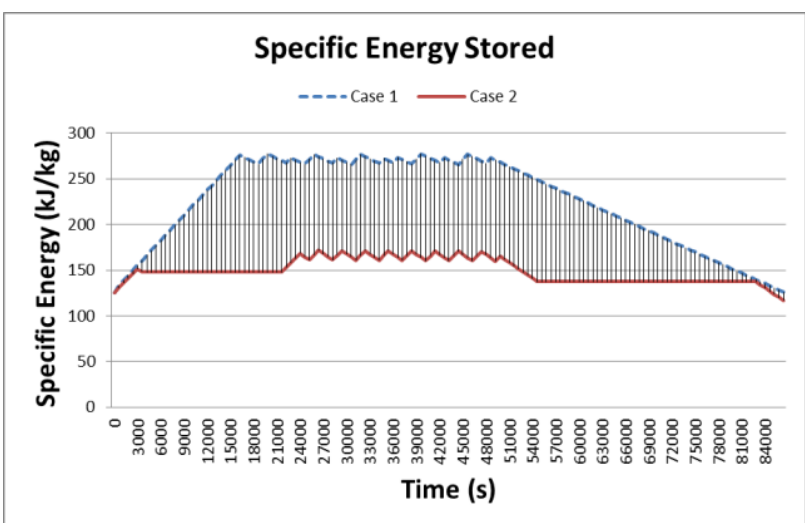

Fig 4. Specific energy stored $(\mathrm{kJ} / \mathrm{kg})$

Following the same trend as in Figure 3, Figure 4 shows how the specific energy available in Case 2 is more stable than in Case 1. This is because the energy stored as latent heat, and leads to a reduction of $30 \%$ in the size of the storage system.

iii. Energy analysis

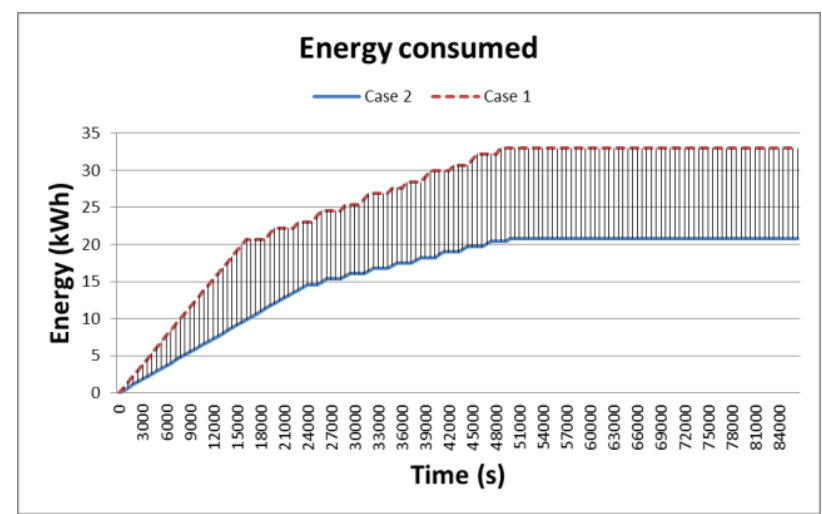

Fig.5 Energy consumed (kWh)

As a result, in Figure 5 we can observe as, to have the same energy accumulated in time, in Case 2 the total energy consumed by the GSHP is dramatically smaller than in Case 1, about 37\%

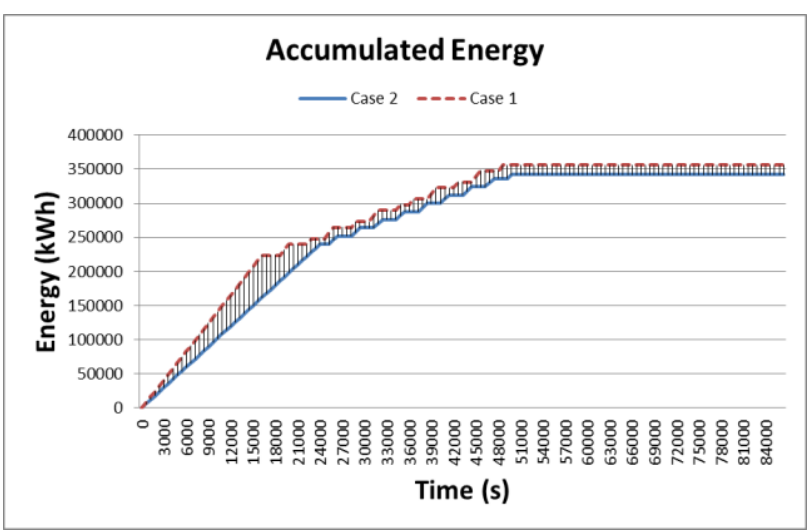

Fig.6 Accumulated energy (kWh)

Figure 6 shows that the final stored energy along time is the same for both cases, obviously due to the fact that it has been our design starting point. The difference between Case 1 and Case 2 is the speed of energy accumulation, which is higher in Case 1 with respect to Case 2, because of the higher temperature in the sensible TES.

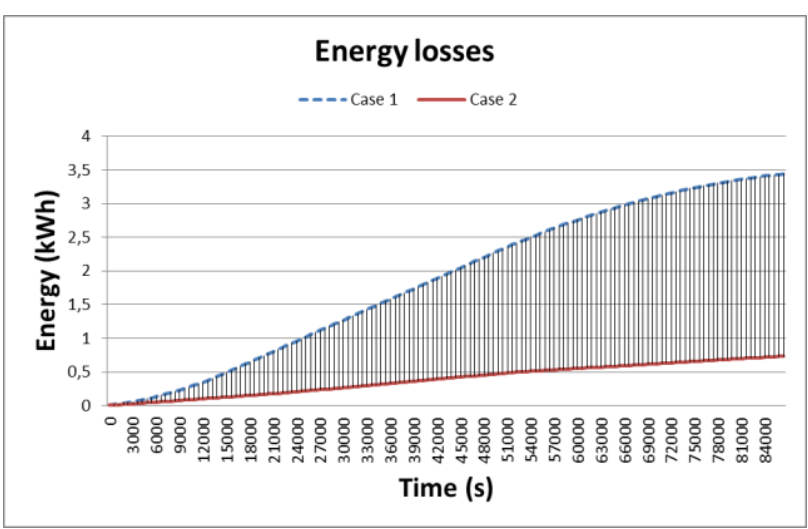

Fig 7 Energy losses $(\mathrm{kWh})$

Figure 7 shows how the energy losses are greater in Case 1 (sensible TES) than in Case 2 (latent TES), as previously stated. Relative reduction in energy losses is estimated to be of $70 \%$.

\section{iv. Exergy analysis}

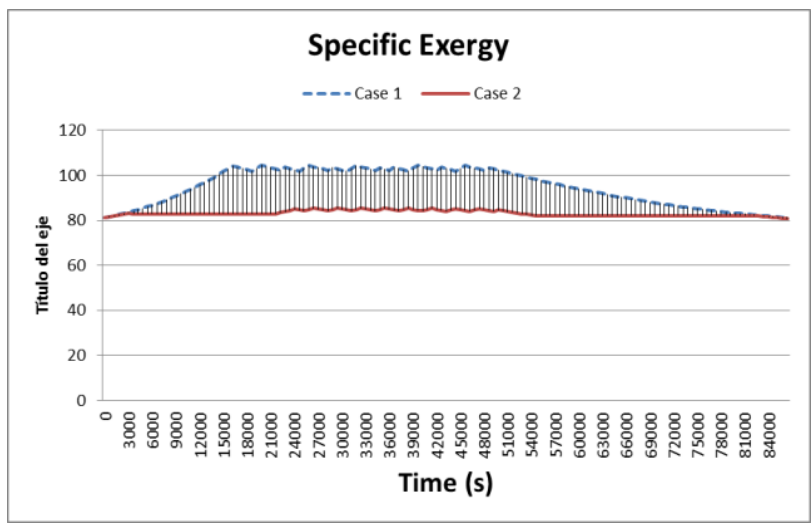

Fig 8 Specific exergy $(\mathrm{kJ} / \mathrm{kg})$

Finally, Figure 8 shows how the specific exergy is the same at the beginning and at the end of the cycle in both cases, but is higher in the intermediate stages in Case 1.

\section{Conclusion}

This paper has presented the simulation and feasibility of a GSHP+PCM facility, designed to meet the domestic hot water (DHW) and heating energy needs of a standard single family house placed in a European continental climate. A simulation software has been used to obtain some energy parameters. Two case study have been compared, namely a GSHP + sensible TES (water) and a GSHP + latent TES (PCM). Using PCMs in the TES we obtain the following advantages: (a) $37 \%$ savings in energy consumption; (b) reduction of $30 \%$ in the space needed for our facility.

\section{Acknowledgement}

We acknowledge support for this research to the firm ENERFUTURE S.L.L., Spain, project on "Integration of low-temperature storage and renewable energy systems 
in air-conditioning of small scale buildings", ENERFUTURE-Universidad de Burgos, 2010.

This contribution is part of the Thesis Doctoral of J. M. García-Alonso.

\section{References}

[1] Directive 2010/31/EU, of the European Parliament and of the Council of 19 May 2010 on the energy performance of buildings (recast).

[2] I. Dinçer, M. A. Rosen, Thermal Energy Storage Systems and Applications, Wiley, London (2011).
[3] J. Mazo, M. Delgado, J. M. Marín, B. Zalba, "Modeling a radiant floor system with Phase Change Material (PCM) integrated into a building simulation tool: Analysis of a case study of a floor heating system coupled to a heat pump", Energy and Buildings 47 (2012), pp. 458-466.

[4] L. F. Cabeza, A. Castell, C. Barreneche, A. De Gracia, A. I. Fernández, "Materials used as PCM in thermal energy storage in buildings: A review", Renewable and Sustainable Energy Reviews 15 (2011), pp. 1675-1695.

[5] C. Solé, "Use of Phase Change Materials (PCM) in combisystem for its energetic optimization”, Thesis Doctoral, University of Lleida, Spain, (2009).

[6] J. M. García-Alonso, F. Aguilar, E. Montero, "Energy storage test module for medium-low temperature water supply", Proc. 12th International Conference on Energy Storage Innostock 2012, pp. 236-237. 